\title{
Premature ovarian insufficiency: evaluation and management
}

\author{
Karuppiah Dharshini ${ }^{1}$, Noel P Somasundaram ${ }^{2}$ \\ Sri Lanka Journal of Diabetes, Endocrinology and Metabolism 2012; 2: 39-42
}

\begin{abstract}
Impairment of ovarian function before the age of 40 years is defined as premature ovarian insufficiency (POI). Alteration of normal menstrual pattern is the commonest presentation of POI and two serum follicle stimulating hormone $(\mathrm{FSH})$ measurements in the menopausal range at least a month apart is diagnostic. Once the possibility of pregnancy is excluded, evaluation of POI should include initial laboratory evaluation of $\mathrm{FSH}$, leutinizing hormone ( $\mathrm{LH})$, estradiol, serum prolactin and thyroid status. A possible etiology should be determined by karyotyping, screening for FMR1 premutations, testing autoimmune markers such as anti-21 hydroxylase antibodies and imaging with pelvic ultrasonography. Management should address psychological well being, ovarian hormone replacement, and restoration of fertility. Management of associated endocrinopathies, co-morbidity and genetic counseling are also of great relevance.
\end{abstract}

\section{Introduction}

Premature ovarian insufficiency (POI) is defined as impaired ovarian function before the age of 40 years which is more than 2 standard deviations below the mean age of normal menopause. It is characterized by amenorrhea for 6 months or more with an elevation of gonadotropin (FSH) levels in two serum samples obtained a month apart (1). Early diagnosis and treatment are the keys to preventing the complications of POI (2). Hence, in patients who present with menstrual irregularity, which may be the first indication of ovarian insufficiency, deserve appropriate evaluation at the first clinic visit (3). However, the diagnosis is usually delayed in most patients.

\section{Clinical evaluation}

Menstrual irregularity has been the commonest presentation of POI. It can vary from amenorrhea, period of oligomenorrhoea to dysfunctional uterine bleeding. POI can also occur following delivery and after stopping oral contraceptives. However, there is no typical menstrual pattern that could suggest the onset of spontaneous premature ovarian insufficiency.

Once the possibility of a pregnancy is excluded, the clinical evaluation must be aimed at establishing the diagnosis of POI, clarifying its etiology and screening for associated complications. Although vasomotor symptoms and vaginal dryness are common due to estrogen deficiency, $50 \%$ of women may produce estrogen and ovulate intermittently. Nevertheless, approximately 5-10 percent of women affected by POI can even conceive and have a normal pregnancy $(4,5)$. During patient evaluation, it is important to address the details of any chronic ill health, adequacy of caloric intake, exercise, emotional stress, prior radiation and chemotherapy, features of autoimmune disorders and family history (Table 1) that might have contributed to the problem. Approximately $10 \%$ of women with premature ovarian failure have a familial basis (6) and therefore assessment of family history is important in all subjects.

The initial laboratory evaluation should include FSH, LH, estrdiol, serum prolactin and thyroid status (7). Two FSH levels more than $40 \mathrm{mIU} / \mathrm{mL}$ by radio immune assay, measured at least one month apart, confirms the diagnosis of POI. In most women with spontaneous POI, FSH is higher than LH, whereas in autoimmune oophoritis LH is markedly elevated (8). Early follicular phase estradiol will be less than the concentrations of women with normal cycles. Serum prolactin should be measured to determine whether the symptoms are caused by hyperprolactinemia.

Karyotyping should be performed in all the patients irrespective of the absence of stigmata of Turner syndrome. FMR1 premutation has been described to be responsible for $14 \%$ of familial cases of POI and $2 \%$ of spontaneous POI (9). When there is no apparent cause for the POI, many health professionals recommend FMR1 premutation screening (10).

Nearly $3 \%$ of women with POI will have positive antiadrenal antibodies (11); therefore measurement of serum anti-adrenal and anti-21 hydroxylase antibodies should be considered in patients with POI. Careful evaluation for adrenal insufficiency is required for those with positive antibodies. Currently, ovarian antibody assays that are available commercially are of little diagnostic value because of problems with specificity and sensitivity (12).

${ }^{1}$ Senior Registrar in Endocrinology, ${ }^{2}$ Consultant Endocrinologist, National Hospital of Sri Lanka, Colombo.

Vol.2, No.1, February 2012 
Pelvic ultrasound examination is useful to identify multifollicular ovaries, which would suggest either autoimmune oophoritis or 17 - 20 desmolase deficiency. Ovarian biopsy has no proven clinical benefit in managing premature ovarian failure and is not recommended. Bone density scan (DEXA) to evaluate bone mineral density must be performed routinely. Fasting blood glucose, antinuclear antibody, rheumatoid factor, liver and renal profile tests are required if clinically indicated.

\section{Management}

The diagnosis of POI is disturbing for the individual patient and therefore management must address the psychological well being, ovarian hormone replacement, and restoration of fertility. In addition, management of associated endocrinopathies and related diseases, coupled with genetic counselling in those with abnormal karyotpe and FMR1 premutations need to be addressed (Table 1).

\section{Psychological support}

Most women are not prepared for the diagnosis of POI and therefore this should be divulged in a sensitive and caring manner. Accurate information regarding the diagnosis, nature of the disease and available sources for information and support should be provided. Physician must allow the patient enough time to accept the diagnosis and explain that POI is not menopause, but spontaneous ovarian activity and pregnancies are yet possible. Decisions regarding family planning can be made once the patient has had some time to come to terms with her condition.

\section{Ovarian hormone replacement}

Women with premature ovarian failure are at an increased risk of developing osteoporosis (13) and coronary heart disease. They have significant vascular endothelial dysfunction, which is restored to normal by estrogen therapy $(14,15)$. Cyclical hormonal therapy with estrogens and progestins is considered necessary in all women with POI to relieve the symptoms of estrogen deficiency and to maintain bone mineral density. The functioning premenopausal ovary produces $17 \beta$-estradiol as the principal estrogen and maintains an average serum estradiol concentration of about $100 \mathrm{pg} / \mathrm{mL}$ (16). Estrogen replacement should be physiological and mimic normal ovarian function. Currently, this is available as oral and transdermal preparations, while the latter are more physiological with several advantages over the oral preparations (Table 2).

Bone mineral density (BMD) should be routinely measured and bone protection measures such as weight bearing exercises, a healthy diet, adequate calcium and vitamin $\mathrm{D}$ intake and avoiding smoking should be emphasized. Bisphophonates are not recommended due to its long skeletal half life and uncertain effects on fetus (17). Preventing and managing obesity and other cardiovascular risk factors are also important in these patients.

Table 1. Clinical indicators for evaluating causes of POI and its associations

\begin{tabular}{lll}
\hline Condition & Clinical features & Tests \\
\hline $\begin{array}{l}\text { Chromosomal defects (Turner } \\
\text { syndrome and } \mathrm{x} \text { chromosomal } \\
\text { abnormalities) }\end{array}$ & $\begin{array}{l}\text { Short stature, low posterior hairline, } \\
\text { shield chest with widely spaced nipples, } \\
\text { wide carrying angle }\end{array}$ & Karyotype \\
Autoimmune disorders & $\begin{array}{l}\text { Goiter, features of hypothyroidism, } \\
\text { Increased skin pigmentation, } \\
\text { orthostatic hypotension consistent } \\
\text { with Addison disease. }\end{array}$ & $\begin{array}{l}\text { TSH,FT4, and anti-TPO antibodies } \\
\text { Serum anti-adrenal and anti-21 } \\
\text { hydroxylase antibodies } \\
\text { ACTH stimulation test }\end{array}$ \\
& $\begin{array}{l}\text { Family history, intellectual disability, } \\
\text { dementia, tremor or ataxia }\end{array}$ & FMR1 premutations \\
& $\begin{array}{l}\text { History of radio and chemo therapy, } \\
\text { Viral infections } \\
\text { Galactosemia, cataracts }\end{array}$ & $\begin{array}{l}\text { Galactose-1-phosphate uridyl } \\
\text { transferase activity }\end{array}$ \\
\hline
\end{tabular}

TSH - thyroid stimulating hormone; FT4 - free thyroxine; TPO - thyroid peroxidase; ACTH - adreno cortico hormone 
Table 2. Pharmacological agents used in the management of POI

\begin{tabular}{|c|c|c|}
\hline Drug & Dose & Comments \\
\hline $\begin{array}{l}\text { Estradiol } \\
\text { Transdermal patch }\end{array}$ & $100 \mu \mathrm{g} /$ day & $\begin{array}{l}\text { Provides } 17 \beta \text {-estradiol } \\
\text { Avoids the first pass effect on the liver } \\
\text { Lower risk of venous thrombo embolism than } \\
\text { oral estrogen } \\
\text { Patch may fall off or cause skin irritation }\end{array}$ \\
\hline Oral estradiol & $2-4 \mu \mathrm{g} /$ day & Variable bio availability \\
\hline $\begin{array}{l}\text { Conjugated equine estrogens } \\
\text { [CEE }]\end{array}$ & $1.25 \mu \mathrm{g} /$ day & \\
\hline Progestins & $10 \mathrm{mg}$ daily for $10-12$ days & \\
\hline Medroxyprogesterone acetate & each month & \\
\hline Micronized progesterone & $\begin{array}{l}200 \mathrm{mg} \text { daily for } 10-12 \text { days } \\
\text { each month }\end{array}$ & \\
\hline Elemental calcium & $1200 \mathrm{mg} /$ day & \\
\hline Vitamin D3 & $800-1000 \mathrm{IU} /$ day & $\begin{array}{l}\text { Maintain adequate vitamin D status } \\
\text { ( } 25 \text { hydroxy vitamin D level of } 30 \mathrm{ng} / \mathrm{mL} \text { ) }\end{array}$ \\
\hline
\end{tabular}

\section{Family planning and fertility}

Although the rate of conception is very low, they still have a remote chance of spontaneous ovulation and natural conception. Estrogen replacement therapy can improve the chances of pregnancy by theoretically lowering the LH levels to normal range and preventing premature luteinization of the remaining follicles. Estrogen hormone replacement treatment does not prevent ovulation and conception in these patients and pregnancy test needs to be performed if they fail to menstruate when expected. Effectiveness of oral contraceptives has not been demonstrated in this population and another form of contraceptive method (barrier method or intra uterine device) is advised if contraception is desired (18).

Nevertheless, the potentially beneficial effect of estrogens on fertility yields very low pregnancy rates. There is no established treatment to restore ovulation and fertility in women with POF. Attempts to treat with exogenous gonadotropins could theoretically exacerbate unrecognized autoimmune ovarian failure (19) and currently available options to resolve infertility include change of family building plans, such as adoption, ovum donation or embryo donation. Success rate of in-vitro fertilization with donor oocytes depend primarily on the age of the oocyte donor and the pregnancy rates are similar irrespective of the age of the women with POI.

\section{Autoimmune disorders}

Patients with POI are at a greater risk of developing other autoimmune disorders. All patients with POI should be educated regarding the symptoms of adrenal insufficiency and the importance of adrenal evaluation (18). Those with positive adrenal antibodies should undergo an annual evaluation for adrenal insufficiency by the corticotrophin stimulation testing. These patients are also at a high risk of developing autoimmune hypothyroidism and have to be screened for this condition. Several other autoimmune disorders such as polyglandular syndrome, myasthenia gravis, rheumatoid arthritis, systemic lupus erythematosus and dry eye syndrome are associated with spontaneous POI and need evaluation if clinically indicated.

\section{References}

1. Rebar RW, Connolly HV. Clinical features of young women with hypergonadotropic amenorrhea. Fertil Steril 1990; 53 : 804.

2. Alzubaidi NH, Chapin HL, Vanderhoof VH, et al. Meeting the needs of young women with secondary amenorrhea and spontaneous premature ovarian failure. Obstet Gynecol 2002; 99: 720.

3. Mishell DRJ, Stenchever MA, Droegemueller W, Herbst AL. Primary and Secondary Amenorrhea. Comprehensive Gynecology. St. Louis: Mosby, 1997: 1043.

4. Nelson LM, Anasti JN, Kimzey LM, et al. Development of luteinized graafian follicles in patients with karyotypically normal spontaneous premature ovarian failure. J Clin Endocrinol Metab 1994; 79: 1470. 
5. Van Kasteren YM, Schoemaker J. Premature ovarian failure: a systematic review on therapeutic interventions to restore ovarian function and achieve pregnancy. Hum Reprod Update 1999; 5: 483

6. Van Kasteren YM, Hundscheid RD, Smits AP, et al. Familial idiopathic premature ovarian failure: an overrated and underestimated genetic disease? Hum Reprod 1999; 14: 2455.

7. Practice Committee of the American Society for Reproductive Medicine. Current evaluation of amenorrhea. Fertil Steril 2004; 82.

8. Welt CK, Falorni A. Selective theca cell dysfunction in autoimmune oophoritis in multifollicular development, decreased estrogen, elevated inhibin B level. JCEM 2005; 90(5): 3069 .

9. Sherman SL. Premature ovarian failure in the fragile $X$ syndrome. Am J Med Genet 2000; 97: 189.

10. ACOG Committee opinion. No. 338: Screening for fragile X syndrome. Obstet Gynecol 2006; 107: 1483.

11. Bakalov VK, Vanderhoof VH, Bondy CA, Nelson LM. Adrenal antibodies detect asymptomatic auto-immune adrenal insufficiency in young women with spontaneous premature ovarian failure. Hum Reprod 2002; 17: 2096.

12. Novosad JA, Kalantaridou SN, Tong ZB, Nelson LM. Ovarian antibodies as detected by indirect immunofluorescence are unreliable in the diagnosis of autoimmune premature ovarian failure: a controlled evaluation. BMC Womens Health 2003; 3: 2.

13. Gallagher JC. Effect of early menopause on BMD and fractures. Menopause 2007; 14: 567-71.

14. Kalantaridou SN, Naka KK, Papanikolaou E, et al. Impaired endothelial function in young women with premature ovarian failure: normalization with hormone therapy. J Clin Endocrinol Metab 2004; 89: 3907.

15. Ostberg, JE, Storry, C, Donald, AE, et al. A dose-response study of hormone replacement in young hypogonadal women: effects on intima media thickness and metabolism. Clin Endocrinol (Oxf) 2007; 66: 557.

16. Mishell DR Jr, Nakamura RM, Crosignani PG, et al. Serum gonadotropin and steroid patterns during the normal menstrual cycle. Am J Obstet Gynecol 1971; 111: 60.

17. Drake MT, Clarke BL, Khosla S. Bisphosphonates: mechanism of action and role in clinical practice. Mayo Clin Proc 2008; 83: 1032 - 45.

18. Nelson LM. Clinical practice. Primary ovarian insufficiency. N Engl J Med 2009; 360: 606.

19. Tidey GF, Nelson LM, Phillips TM, Stillman RJ. Gonadotropins enhance HLA-DR antigen expression in human granulosa cells. Am J Obstet Gynecol 1992; 167: 1768. 